\title{
Dr. Richard C. Nelson: Respected as the Father of the Japanese Society of Biomechanics
}

\author{
Mitsumasa Miyashita \\ The University of Tokyo
}

\begin{abstract}
The reasons for the renaming of the Japanese Society of Kinesiology to the Japanese Society of Biomechanics are explained, and the importance of the International Congress of Biomechanics, the International Society of Biomechanics, and Richard Nelson are outlined.
\end{abstract}

Keywords: International Society of Biomechanics, Japan, kinesiology

Nearly a half century has passed since the International Society of Biomechanics (ISB) was officially established at the Pennsylvania State University in 1973. From 1957 to 1978, biomechanics studies in the field of sports and physical education in Japan had been conducted under the name of "kinesiology." After Japan's educational system was reformed by the Education Mission of the United States after World War II, the word "kinesiology" was more widely adopted by the Japanese. The pioneers organized a small research group of kinesiologists in 1957. The number of researchers of "kinesiology" began to increase early in the 1970s in Japan.

On the other hand, "biomechanics" was used internationally to describe research on the mechanical aspects of human movement, but not in Japan. I made a presentation at the second International Congress of Biomechanics in 1969, titled "The Relation Between Electrical Activity in Muscle and Speed of Walking and Running." At the third Congress in 1971, my colleagues and I gave presentations titled "Analysis of Running Patterns in Relation to Speed"2 and "A Study on the Relations Between Physical Performance and Physical Resources,"3 respectively. I met Dr. Richard Nelson at that Congress and attended his presentation titled "Biomechanics of Sport: An Emerging Discipline."4

When the decision was made to hold the fourth Congress at the Pennsylvania State University, I thought that this Congress might be a good opportunity to provide international stimulation to Japanese researchers. I rounded up the researchers living in Nagoya to present their research results at the fourth Congress in 1973.

In those days, since the income of researchers in Japan was relatively low compared with other developed countries, we had to look for discount group tickets. Then, I tried to recruit other researchers from all over Japan to participate. Finally, a large group of more than 30 of us traveled together to Pennsylvania.

Five presentations were accepted by the Congress's screening committee. For most of my colleagues, this would be their first English oral presentation; therefore, they repeatedly practiced their slide presentations. The titles of the presentations were as follows: "Temporal Patterns in Running,"5 "Contribution of the Body Parts to Throwing Performance," 6 "Biomechanics of Bowling,"7

Miyashita (mm1192@tcn-catv.ne.jp) is with the Division of Physical and Health Education, Graduate School of Education, The University of Tokyo, Tokyo, Japan.
"Photographic Method of Analyzing the Pressure Distribution of the Foot Against the Ground," 8 and "A Study of Stability of Standing Posture." 9 Revisions were made to those drafts by the editors, Richard Nelson and Chauncey Morehouse, and subsequently published by University Park Press in Volume IV of Biomechanics in 1974.

When the ISB was officially formed at the fourth Congress, most Japanese participants felt that the name "biomechanics" was more suitable for them than the term "kinesiology." The Japanese Society of Kinesiology was then changed to Japanese Society of Biomechanics (JSB) in 1978. The JSB invited Dr. Nelson to the National Congress, which was then held biannually, to present an invited lecture. He gave additional special lectures on biomechanics at several universities during his stay in Japan.

Accepting Dr. Nelson's suggestion, the researchers living in Nagoya proposed organizing and hosting the ISB Congress. A total of 419 researchers, including 271 Japanese, participated in the eighth Congress of the ISB held in Nagoya, Japan, in 1981, which was very successful. The proceedings consisted of 2 large volumes, which were published as Biomechanics VIII-A and VIII-B (edited by P.V. Komi) by University Park Press in 1983. Thus, since the International Congress of Biomechanics was held in Penn State University 1973, JSB rapidly developed in both national and international aspects in only a decade. Therefore, it is no exaggeration to call Professor Nelson "the father of the JSB." Thereafter, the 16th Congress of the ISB was held in Tokyo in 1997, and in 2023, both the 29th Congress of the ISB and the 29th Congress of the Japanese Society of Biomechanics will be held in Fukuoka, Japan.

Organizers of these international scientific congresses usually prepare a 1-day excursion or recreational activities for the attendees. The Congress Office at Penn State University provided several activities, but not something we had come prepared for: fishing. As we had brought our fishing equipment from Japan, we asked whether there was a place to fish near the university. Fortunately, one of volunteers at the Congress guided us to a fishing stream on private land owned by her father. We could catch brown trout of good size (Figure 1). Moreover, on the way back to our hotel, she let us drop in at her brother's farm, where we ate fresh sweet corn. These experiences were unexpected joys to us at the fourth International Congress of Biomechanics hosted by Penn State University. 


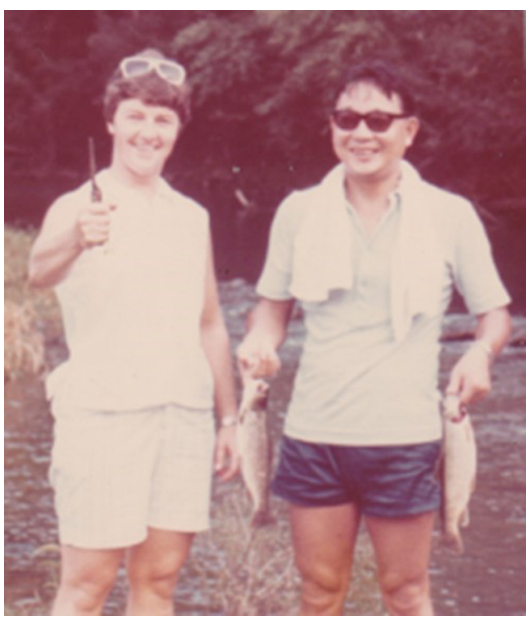

Figure 1 - The author holding the results of his fishing trip.

\section{References}

1. Miyashita M, Matsui H, Miura M. The relation between electrical activity in muscle and speed of walking and running. In: Vredenbregt J, Wartenweiler J, eds. Biomechanics II. Vol 6. Basel, Switzerland: Karger Publishers; 1971:192-196.
2. Hoshikawa T, Matsui H, Miyashita M. Analysis of running pattern in relation to speed. In: Cerquiglini S, Venerando A, Wartenweiler J, eds. Biomechanics III. Vol 8. Basel, Switzerland: Karger Publishers; 1973: 342-348.

3. Miyashita M, Miura M, Kobayashi K, Hoshikawa T. A study on relations between physical performance and physical resources. In: Cerquiglini S, Venerando A, Wartenweiler J, eds. Biomechanics III. Vol 8. Basel, Switzerland: Karger Publishers; 1973:349-353.

4. Nelson RC. Biomechanics of sport: Emerging discipline. In: Cerquiglini S, Venerando A, Wartenweiler J, eds. Biomechanics III. Vol 8. Basel, Switzerland: Karger; 1973:336-341.

5. Saito M, Kobayashi K, Miyashita M, Hoshikawa T. Temporal patterns in running. In: Nelson RC, Morehouse CA, eds. Biomechanics IV. Baltimore, MD: University Park Press; 1974:106-111.

6. Toyoshima S, Hoshikawa T, Miyashita M, Oguri T. Contribution of the body parts to throwing performance. In: Nelson RC, Morehouse CA, eds. Biomechanics IV. Baltimore, MD: University Park Press; 1974:169-174.

7. Murase Y, Miyashita M, Matsui H, Mizutani S, Wakita H. Biomechanics of bowling. In: Nelson RC, Morehouse CA, eds. Biomechanics IV. Baltimore, MD: University Park Press; 1974:291-297.

8. Miura M, Miyashita M, Matsui H, Sodeyama H. Photographic method of analyzing the pressure distribution of the foot against the ground. In: Nelson RC, Morehouse CA, eds. Biomechanics IV. Baltimore, MD: University Park Press; 1974:482-487.

9. Kobayashi K, Miura M, Yoneda Y, Edo K. A study of stability of standing posture. In: Nelson RC, Morehouse CA, eds. Biomechanics $I V$. Baltimore, MD: University Park Press; 1974:53-59. 